\title{
Effectiveness of pelvic floor muscles training on females' sexual function throughout pregnancy and postpartum
}

\author{
Tyseer Marzouk*1, Hanan Nabil ${ }^{2}$ \\ ${ }^{1}$ Woman's Health and Midwifery Nursing, Faculty of Nursing, Mansoura University, Egypt \\ ${ }^{2}$ Obstetrics and Gynaecology, Faculty of Medicine, Mansoura University, Egypt
}

Received: April 20, 2020

DOI: $10.5430 /$ cns.v8n2p21
Accepted: May 21, 2020

Online Published: June 2, 2020

URL: https://doi.org/10.5430/cns.v8n2p21

\begin{abstract}
Objective: This study aimed to evaluate effectiveness of pelvic floor muscles training on females' sexual function throughout pregnancy and postpartum.

Methods: A quasi experimental research design was applied at the antenatal clinic of Mansoura University hospital, Egypt. A purposive sample of 72 nulliparous singleton pregnant clients free from any connotation affect sexual practice was studied. The subjects were allocated into two groups; the control group received conventional antenatal and postnatal care, while the intervention group received the same care besides performing pelvic floor muscle exercise from 20 weeks of pregnancy until 10-12 weeks postpartum. Female sexual function, sexual quality of life, and strength of the pelvic floor muscle contraction were evaluated at baseline, at 28-30 weeks gestation, and at 10-12 weeks postpartum, by using the female sexual function index scale, sexual quality of life-female, and the Oxford grading scale.

Results: The total female sexual function index scores in the intervention group were higher than those of the control group at the pregnancy and postpartum follow ups $(22.3 \pm 6.9$ vs. $15.9 \pm 6.8 \& 26.0 \pm 6.7$ vs. $13.5 \pm 6.3$ respectively; $p<.001)$. The sexual quality of life-female scores were significantly higher in the intervention group than in the control group at the pregnancy follow up evaluation $(54.2 \pm 15.9$ vs. $36.9 \pm 9.7$ respectively, $p<.001)$ and at the postpartum follow up evaluation $(59.8 \pm 13.5$ vs. $30.3 \pm 7.0$ respectively, $p<.001$ ). The pelvic floor muscles strength was significantly better in the intervention group than in the control group at the pregnancy follow up evaluation and at the postpartum follow up evaluation.

Conclusions: Pelvic floor muscle training during early gestation weeks was an effective tool for improvement of the female sexual function, sexual quality of life-female, and pelvic floor muscles strength during pregnancy and postpartum. Thus, it should be encouraged for pregnant mothers at early weeks and continued till postpartum.
\end{abstract}

Key Words: Female sexual function, Sexual quality of life, Pelvic floor muscles, Sexual domains

\section{INTRODUCTION}

Sexual function is a basic human need and an intimate part of human life. ${ }^{[1]}$ Unstable sexual relationship badly influences the individual's general wellbeing, causes mental tension between the couples and carries undeniable influence on the quality of life. Research studies revealed that sexual dysfunction is correlated with feelings of low self-esteem, emotional dissatisfaction, and adversely affects interpersonal

\footnotetext{
*Correspondence: Tyseer Marzouk; Email: tm_fathy@yahoo.com; Address: Woman’s Health and Midwifery Nursing, Faculty of Nursing, Mansoura University, Egypt.
} 
relationships. ${ }^{[2]}$

Pregnancy is a critical period in which women need more intimacy with her husband, otherwise, it might be even harder. Unfortunately, sexual function is negatively affected during pregnancy and postpartum periods. It was evidenced that the prevalence of sexual dysfunction is between $23 \%$ and $47 \%$ among $2^{n d}$-trimester pregnant women, between $46 \%$ and $73 \%$ among 3rd-trimester pregnant women, and from $43 \%$ to $83 \%$ of postnatal mothers reported sexual dysfunction. ${ }^{[3,4]}$

Even though psychological and social variables have an essential role in sexual problems, the role of the physical factors; specifically pelvic floor muscle (PFM) strength, cannot be denied. ${ }^{[5,6]}$ Pregnancy-associated hormonal changes; such as increased progesterone level, results in a reduction in tone of the PFM which plays a vital role in sexual intercourse. It has been evidenced that strong PFM is the main party in vaginal receptivity, where it increases vaginal blood flow, thus improves vaginal sensation and augment orgasmic muscular response. ${ }^{[7]}$ Given that evidence, weakened muscles are associated with vaginal hypoesthesia, anorgasmia and adversely affects the sexual function.

Among various available approaches for correcting weakened PFM, none is free from complications. The pelvic floor muscle exercise (PFME) is painless, costless, available to be done during day and night, and carries no side effects. ${ }^{[6]}$ Despite that, over 200 millions women in the world are not alert to its valuable effects and around half of the women perform it incorrectly. ${ }^{[8]}$

Some earlier studies demonstrated that strong PFM is linked with better sexual pleasure, desire, vaginal lubrication, orgasm, enhanced vaginal sensation and tightness. ${ }^{[9,10]}$ Meanwhile, others failed to confirm the significant effect of the PFM training on the sexual function. ${ }^{[11,12]}$ The wide difference between the previous findings as inconclusive suggests more research studies. Therefore, the present study was carried out to evaluate effectiveness of pelvic floor muscles training on females' sexual function throughout pregnancy and postpartum.

\subsection{Significance of the study}

Previous reviews about the efficacy of the PFM training on female sexual function revealed heterogeneity and little evidence. Sexual dysfunction affects a high number of Egyptian women. A cross-sectional clinic-hospital based survey found pregnancy and childbirth-related events account for $18.8 \%$ of the causes of sexual dysfunction. The majority of the affected women $(84.5 \%)$ did not receive assistance for their sexual problems. ${ }^{[13]}$ This stimulated the present study to evaluate effectiveness of pelvic floor muscles training on females' sexual function throughout pregnancy and postpartum.

\subsection{Aim of the study}

The present study aimed to evaluate effectiveness of pelvic floor muscles training on females' sexual function throughout pregnancy and postpartum.

\subsection{Hypotheses of the study}

To achieve the aim of the present study, three hypotheses were tested:

Hypothesis I: "Pregnant women who train their pelvic floor muscles during the pregnancy and postpartum period, show a significant increase of the total female sexual function index and sexual domains scores compared to those who do not train".

Hypothesis II: "Pregnant women who train their pelvic floor muscles during the pregnancy and postpartum period, demonstrate a significant increase of the sexual quality of lifefemale score compared to those who do not train".

Hypothesis III: "Pregnant women who train their pelvic floor muscles during the pregnancy and postpartum periods, exhibit a significant improvement in the pelvic floor muscles degree of contraction; according to the Oxford grading scale, compared to those who do not train".

\section{SUBJECTS AND METHODS}

\subsection{Research design}

A quasi-experimental research design was utilized in this study. This design was selected to find the effect of manipulating the independent variable (i.e., pelvic floor muscles training) on the dependent variables (i.e., female sexual function, sexual quality of female-life, and strength of the pelvic floor muscles). Two parallel groups were involved without attempts for randomization. The control group received the conventional antenatal and postpartum care, while the intervention group performed pelvic floor muscles training beside conventional care.

\subsection{Study setting}

The current study was conducted at the antenatal care clinic. It is one of the outpatient clinics of the Obstetrics and Gynecology department, Mansoura University Hospitals-Egypt. Such a clinic is assigned for the follow-up of the pregnant mothers and their fetuses. Along with a neighboring room for participants' reception and training. The room was prepared with an adequate number of seats and supportive materials (e.g., Bed, Pelvic model, Flip-charts, Laptop, etc.). 


\subsection{Sampling}

The Obstetrics and Gynecology department board approval was taken for conducting the current study. Recruiting a purposive sample of 72 pregnant mothers was done between February and April 2016. The sample was collected by inviting each nulliparous singleton pregnant client; attended the antenatal clinic at 20 to 22 weeks gestation, to share in current research work. Recruitment was completed within three months and potential participants were followed-up during pregnancy until 10 to 12 weeks postpartum. Clients were screened for meeting the following inclusion criteria:

(1) Sexually active for at least 6 months prior to enrollment and on an ongoing sexual relationship.

(2) Can read and write to fill in the questionnaires.

(3) Free from medical or anatomical conditions that are adversely affecting the sexual function; such as cardiovascular disease or vaginismus respectively. Free from obstetric problems that are limiting sexual practice (e.g., placenta previa, or threatened preterm labor), or predisposing to Cesarean section. Potential participants were excluded if any indication for Cesarean section developed during pregnancy or childbirth. Additionally, women who had given vaginal delivery with 2nd, 3rd, or 4th-degree perineal tears were excluded.
(4) Not on a medical therapy that is expected to affect the female's sexual function such as antihypertensive drugs.

(5) The husband is free from any mental or physical problems affecting sexual function.

\subsubsection{Sample size}

This quasi-experimental study intends to evaluate effectiveness of pelvic floor muscles training on females' sexual function throughout pregnancy and postpartum. Taking into consideration, the mean score of the female sexual function index of 23.09 from a previous study by Malakoti et al., $2012,{ }^{[14]}$ with a significance level of 0.05 , power of 0.80 , and an expected increase in the mean FSFI score with $15 \%$, the sample size was calculated using the following Equation 1:

$$
\frac{\left[\left(Z_{\frac{\alpha}{2}}+Z_{\beta}\right)^{2} \times\left\{2(S D)^{2}\right\}\right]}{(\text { mean difference between the two groups })^{2}}
$$

where $S D=$ standard deviation, $Z_{\frac{\alpha}{2}}$ : This depends on the level of significance, for $5 \%$ this is $1.96, Z_{\beta}$ : This depends on power, for $80 \%$ this is 0.84 . Therefore, $n=\left[(1.96+0.84)^{2}\right.$ $\left.\times 2(5.3)^{2}\right] /(23.1-19.6)^{2}=35.9$. Accordingly, the sample size required per group was 36 .

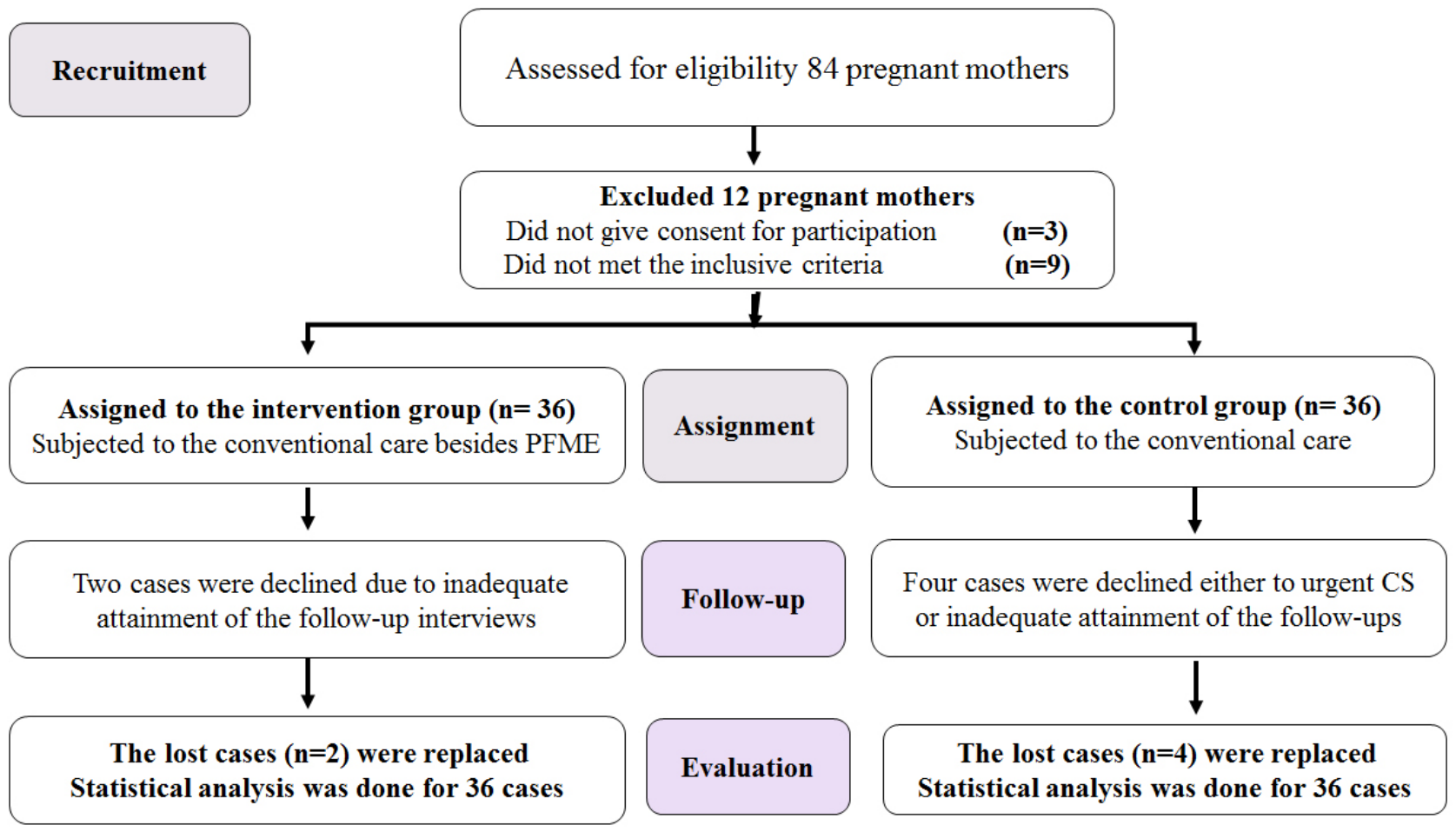

Figure 1. Flowchart of the study participation 


\subsubsection{Recruitment and groups' assignment}

Eligibility for participation was determined by taking the client's history from those who attended the antenatal clinic during the recruitment period. To recruit the assigned sample size, 84 pregnant mothers were interviewed to assess their eligibility for participation. Among those, 12 were excluded; 3 refused to share in the study and 9 were not eligible for participation. The remaining 72 pregnant mothers assigned either to the intervention or to the control groups; without any attempt for randomization. During the study period 2 cases from the intervention group and 4 cases from the control group declined their follow-up visits; due to two reasons (i.e., 3 cases required urgent Cesarean section, 3 cases did not attain the minimal number of interviews). The total declined cases $(n=6)$ were replaced and statistical analysis was done for 72 cases. The flowchart of the analyzed sample is illustrated in Figure 1.

\subsection{Measures of data collection}

Three tools were used to collect the required data in the current study. The Female Sexual Function Index (FSFI), Sexual Quality of Life-Female (SQL-F) questionnaires, and the Modified Oxford Grading Scale.

\subsubsection{Female Sexual Function Index (FSFI)}

The Female Sexual Function Index is a brief multidimensional self-report questionnaire. It is used to describe the key dimensions of the female sexual function during the four weeks prior to the interview day. It comprises 19 multiple choice questions; distributed on 6 sexual domains (i.e., desire, arousal, lubrication, orgasm, satisfaction, and sexual pain). The 1 st domain described by 2 questions, the 2 nd and 3rd domains described each by 4 questions, while the last 3 domains each described by 3 questions.

Each domain scored from 0/1 (no sexual activity or sexual dysfunction respectively) to 5 (suggestive of normal sexual activity). The domain score determined by adding the score of the questions that comprise a domain and multiply the sum by the domain factor. The domain factor of desire is 0.6 , it is 0.3 for arousal and lubrication, while the domain factor of orgasm, satisfaction, and pain is 0.4 . The full-scale score calculated by adding the six domains scores (total score $=$ 2 to 36). In the present study, the researchers used the Arabic version FSFI. The validity and reliability of the Arabic version have been established for the Egyptian population in a study by Anis et al. ${ }^{[15]}$ A total score of 28.1 was taken as the cutoff point for the Arabic version FSFI to distinguish between women with female sexual dysfunction and those with normal function (sensitivity $96.7 \%$, specificity $93.2 \%$ ).

\subsubsection{Sexual Quality of Life-Female questionnaire}

The Sexual Quality of Life-Female (SQOL-F) questionnaire aims to assess the impact of the female sexual dysfunction on a woman's sexual quality of life. It comprises 18 Likert-type statements with six options. Each statement scored between 0 and 5; where 0 refers to completely agree and 5 refers to completely disagree. The total score ranges from 0 to 90 . The higher score indicates a better quality of life. In the current study, the SQOL-F scale was translated into the Arabic language before the recruitment of the study subjects. The translation was based on the original English version and the validity of the Arabic version was asserted by a panel of 5 expertise in the field of Obstetrics nursing and medicine. Validation was verified to make sure that the statements were consistently delivered to women and carried the anticipated meaning that they were designed for. ${ }^{[16]}$

\subsubsection{Modified Oxford grading scale}

The modified Oxford grading system was used to identify the strength of the PFMs. Based on the vaginal examination findings, the strength of the PFMs is identified. The modified Oxford grading system is a 6 points scale: a zero score means the absence of contraction, score 1 was given if there was Flicker contraction, score 2 indicates a weak contraction, score 3 indicates moderate contraction, distinct pressure on the examining finger, and palpable upward and forward movement, score 4 was given in case of good contraction, while the PFM strength was scored 5 if there was a very strong muscle strength, with suction-type effect on the examiner's finger. The exams were done by a trained researcher. ${ }^{[17]}$

\subsection{Ethical considerations}

The research proposal was ethically accepted by the ethics committee of the faculty of nursing and by the Obstetrics and Gynecology department board of Mansoura University. Informed consent was taken from each eligible potential participant before starting the intervention. Data were secured in a secured computer.

\subsection{Research process}

This research was carried out through three phases. Baseline data collection, training the potential participants on how to perform the pelvic floor muscles training, and follow-up and evaluation of the outcomes phases.

\subsubsection{Baseline data collection}

On the day of recruitment, the aim and approach of the study were explained to each potential participant. The basic demographic data were collected and then informed consent was taken from each eligible participant. At the initial interview, the three dependent variables (i.e., female sexual function, 
sexual quality of female-life, and strength of the pelvic floor muscles) were evaluated. Firstly, the pelvic floor muscle strength was identified according to the Modified Oxford Grading Scale. Evaluation of the PFM strength was done according to the following steps: (1) The client was asked to lie in the supine position, bent the knees, and relax muscles of the thighs, buttocks, and abdomen. (2) The client was asked to contract the pelvic floor muscle. This is accomplished by instructing the client to maximally squeeze the band of muscles around the front passage (i.e., ureters) and the back passage (i.e., rectum); like the act done in trying to stop passing urine stream or flatus. (3) Using a sterile gloved hand lubricated by KY gel, a digital examination was done and the strength of the muscles was verified according to the Modified Oxford Grading Scale (see Table 1). To attain as much as possible highest reliability of the findings, the strength of the PFM was evaluated only by one examiner.

Table 1. The Modified Oxford Grading Scale

\begin{tabular}{cc}
\hline Strength of contraction & Score \\
\hline Absent & 0 \\
Flicker & 1 \\
Weak & 2 \\
Moderate & 3 \\
Good & 4 \\
Strong & 5 \\
\hline
\end{tabular}

\subsubsection{Training of the potential participants on how to per- form the pelvic floor muscle exercise}

Training the potential participants on how to perform the pelvic floor muscle exercise was provided in a neighboring room next to the antenatal outpatient clinic. The training was directed to small groups $(n=3-5)$; through a theoretical session followed by practical application. The theoretical session was a PowerPoint presentation on the anatomy of the female pelvis, how to identify the pelvic floor muscle, how to properly contract the muscle, and how to train the muscles in different positions. Thereafter, practical application was done by each participant alone and accuracy was evaluated by the trainer. The theoretical content was provided within 15-20 minutes, while the practical application evaluated by the trainer within 5 minutes for each participant.

\section{The pelvic floor muscles exercise}

The intervention group was taught about how to correctly perform the pelvic floor muscle exercise. This was achieved by instructing each to do the following steps steadily: 1) Take a comfortable position; either lying down or assuming the sitting position. 2) Identifying the pelvic floor muscle by asking the participant to imagine stopping pass of the urine flow and at once holding pass of flatus. 3) The exercise was done by greatly tighten the muscle bands around the vagina and rectum and trying to pull these muscles upwards inside the pelvic cavity. Feeling the pelvic floor muscle pulled up inside the pelvis ensured that the woman used the correct muscle. If a woman cannot feel the PFM contraction, changing the position may be beneficial. The PFM contraction should be followed immediately by a period of relaxation.

Each participant was instructed to complete 2-3 sets of contractions per day. Each set comprised of 8-12 contractions. The period of the contractions was not similar. The first contraction was of a maximum potential power holding for 6-8 seconds followed by 3 shorter contractions and so on until 8-12 contractions were completed. Each contraction was followed by complete relaxation of 10 -seconds. The pelvic floor muscle exercise was started from the day of recruitment until 38 weeks of gestation and then resumed after delivery as soon as the postpartum mother can.

\subsubsection{Follow-up and outcomes evaluation}

Participants' compliance with performing the pelvic floor muscle exercise was monitored by keeping in contact with them; either by telephone conversation or face to face interviews. Telephone conversations were done bimonthly, starting from the 22 weeks of gestation giving a total number of 12 conversations (i.e., at 22, 24, 26, 30, 32, 34, 36, 38 weeks of gestation; and 4, 6, 8, 10 weeks postpartum). Each consumed around 5-10 minutes; in which participants reviewed their performance with the researcher and inquired about any pregnancy concern. Face to face interviews were done at the recruitment day; around 20 weeks of gestation, at 28-30 weeks of gestation and 10-12 weeks postpartum. The interview took about 10-15 minutes. During the interviews, FSFI and SQFL questionnaires were completed and the pelvic floor muscle strength was clinically evaluated. Achieving 8 telephone or face to face interviews were adequate to keep participation in the study.

\section{Outcomes of the study}

The female sexual function, sexual quality of female life, and strength of the pelvic floor muscles were assessed three times for the both groups. Baseline assessment was done at the day of recruitment, while the follow-up assessments were done at 28-30 weeks of gestation and 10 to 12 weeks postpartum.

\section{The control group}

Participant women of the control group received the conventional care. This care was given according to the age of gestation and women's concerns. 


\subsection{Statistical analysis}

All statistical calculations were done through SPSS version 20.0 statistic software. Continuous variables were tested for normality of distribution prior to statistical calculations. All continuous variables were normally distributed and were presented in mean $\pm S D$. Categorical variables were presented in number and percentage. The comparisons were performed using independent sample Student's t-test for comparison between two continuous variables. A Chi-square test was used for comparison of categorical variables. The $95 \%$ con- fidence interval (CI) for the difference between means was also calculated. Statistical significance was set at $p<.05$.

\section{RESULTS}

The basic characteristics of the pregnant mothers in the two groups are demonstrated in Table 2. The pregnant mothers in the PFM training group and in the control group are matched regarding the age of the mothers, the gestational age of the current pregnancy, the body mass index, number of previous abortions, educational level, and the employment status.

Table 2. Basic characteristics of the participants by the study groups $(n=72)$

\begin{tabular}{|c|c|c|c|c|}
\hline \multirow{2}{*}{ Variables } & \multirow{2}{*}{$\begin{array}{l}\text { PFM training group } \\
\qquad(\mathrm{n}=36)\end{array}$} & \multirow{2}{*}{$\begin{array}{c}\text { Control group } \\
(n=36) \\
\end{array}$} & \multicolumn{2}{|c|}{ Student's t test } \\
\hline & & & $t$ & $p$ \\
\hline \multicolumn{5}{|l|}{ Mother's age (years) } \\
\hline Range & $19-31$ & $20-29$ & & \\
\hline Mean $\pm S D$ & $23.4 \pm 3.2$ & $24.3 \pm 2.9$ & 1.24 & .269 \\
\hline \multicolumn{5}{|c|}{ Gestational age (weeks) } \\
\hline Range & $20-22$ & 20-21 & & \\
\hline Mean $\pm S D$ & $20.6 \pm 0.6$ & $20.5 \pm 0.5$ & 0.63 & .529 \\
\hline \multicolumn{5}{|c|}{ Body mass index $\left(\mathrm{kg} / \mathrm{m}^{2}\right)$} \\
\hline Range & $19.0-29.8$ & $19.2-29.9$ & & \\
\hline Mean $\pm S D$ & $24.3 \pm 3.4$ & $24.6 \pm 3.5$ & 0.40 & 689 \\
\hline History of abortion & $5,13.9 \%$ & $4,11.1 \%$ & $0.13^{*}$ & .722 \\
\hline \multicolumn{5}{|l|}{ Education } \\
\hline Illiterate & $10,27.8 \%$ & $9,25.0 \%$ & & \\
\hline Basic & $12,33.3 \%$ & $10,27.8 \%$ & & \\
\hline Higher & $14,38.9 \%$ & $17,47.2 \%$ & $0.53^{*}$ & .769 \\
\hline \multicolumn{5}{|l|}{ Employment } \\
\hline Housewife & $18,50.0 \%$ & $17,47.2 \%$ & & \\
\hline Working & $18,50.0 \%$ & $19,52.8 \%$ & $0.06^{*}$ & .814 \\
\hline
\end{tabular}

Note. ${ }^{*}$ means $\chi^{2}$ test

The Female Sexual Function Index scores at baseline, pregnancy follow-up and post-partum follow-up were compared between the two groups and shown in Table 3. The domains of the FSFI were matched at the baseline between the two groups. However, all the FSFI domains were significantly higher in the PFM training group at the pregnancy follow up evaluation in comparison to the control group. In addition, at the postpartum follow-up, all the FSFI domains showed further improvement and were also significantly higher in the PFM training group in comparison to the control group.

The total FSFI score in the PFM training group was 22.3 \pm 6.9 compared to $15.9 \pm 6.8$ in the control group at the pregnancy follow up. This difference was significant $(95 \%$ $\mathrm{CI}=3.19$ to $9.63, p<.001)$. Similarly, the total FSFI score in the PFM training group was $26.0 \pm 6.7$ compared to 13.5 \pm 6.3 in the control group at the postpartum follow-up. This difference was also significant $(95 \% \mathrm{CI}=9.49$ to $15.60, p<$ .001) (see Table 3 and Figure 1).
The SQOL-F Scores of the two groups were compared at baseline, at pregnancy follow-up, and at post-partum followup and were demonstrated in Table 4 and Figure 3. Despite, the SQOL-F scores did not differ significantly between the two groups at the entry of the study, it was significantly higher in the PFM training group than in the control group at the pregnancy follow up evaluation $(54.2 \pm 15.9$ vs. 36.9 \pm 9.7 respectively, $p<.001)$. The SQOL-F score was also significantly higher in the PFM training group than in the control group at the postpartum follow-up evaluation (59.8 \pm 13.5 vs. $30.3 \pm 7.0$ respectively, $p<.001)$.

The differences in the frequency of the pelvic floor muscles degree of contraction were insignificant at the baseline evaluation between the two groups. However, the pelvic floor muscles strength was significantly better in the PFM training group than in the control group at the pregnancy follow up evaluation $(p=.037)$ and at the postpartum follow-up evaluation $(p=.0014)$ (see Table 5). 
Table 3. Female sexual function index scores at baseline, pregnancy follow-up, and post-partum follow-up the by study groups $(\mathrm{n}=72)$

\begin{tabular}{|c|c|c|c|c|c|c|c|c|}
\hline \multirow[b]{2}{*}{ Domains } & \multicolumn{3}{|c|}{ PFM training group $(n=36)$} & \multicolumn{3}{|c|}{ Control group $(n=36)$} & \multirow{2}{*}{$\begin{array}{c}\text { Mean difference } \\
{[95 \% \mathrm{CI}]}\end{array}$} & \multirow[b]{2}{*}{$p$} \\
\hline & Baseline & $\begin{array}{l}\text { Pregnancy } \\
\text { Follow up }\end{array}$ & $\begin{array}{l}\text { Post-partum } \\
\text { Follow up }\end{array}$ & Baseline & $\begin{array}{l}\text { Pregnancy } \\
\text { Follow up }\end{array}$ & $\begin{array}{l}\text { Post-partum } \\
\text { Follow up }\end{array}$ & & \\
\hline \multirow[t]{3}{*}{ Desire } & $3.0 \pm 0.9$ & $3.8 \pm 1.2$ & $4.3 \pm 0.9$ & $3.2 \pm 1.0$ & $2.7 \pm 1.1$ & $2.4 \pm 1.0$ & $0.18[-0.63$ to 0.27$]$ & .427 \\
\hline & & & & & & & $1.1[0.60$ to 1.64$]$ & $<.001$ \\
\hline & & & & & & & $1.9[1.44$ to 2.34$]$ & $<.001$ \\
\hline \multirow[t]{3}{*}{ Arousal } & $2.6 \pm 1.1$ & $3.1 \pm 1.3$ & $4.1 \pm 1.5$ & $2.5 \pm 1.0$ & $1.9 \pm 1.4$ & $1.7 \pm 1.3$ & $0.03[-0.47$ to 0.52$]$ & .911 \\
\hline & & & & & & & $1.25[0.60$ to 1.90$]$ & $<.001$ \\
\hline & & & & & & & $2.42[1.75$ to 3.08$]$ & $<.001$ \\
\hline \multirow[t]{3}{*}{ Lubrication } & $2.5 \pm 1.1$ & $3.4 \pm 1.1$ & $4.4 \pm 1.2$ & $2.4 \pm 1.0$ & $1.7 \pm 1.3$ & $1.6 \pm 1.2$ & $0.06[-0.44$ to 0.55$]$ & .824 \\
\hline & & & & & & & $1.64[1.07$ to 2.21$]$ & $<.001$ \\
\hline & & & & & & & $2.78[2.16$ to 340$]$ & $<.001$ \\
\hline \multirow[t]{3}{*}{ Orgasm } & $3.5 \pm 1.4$ & $3.8 \pm 1.3$ & $4.1 \pm 1.2$ & $3.3 \pm 1.1$ & $2.9 \pm 1.1$ & $2.6 \pm 1.2$ & $0.19[-0.39$ to 0.78$]$ & .510 \\
\hline & & & & & & & $0.86[0.30$ to 1.42$]$ & .003 \\
\hline & & & & & & & $1.47[0.91$ to 0.203$]$ & $<.001$ \\
\hline \multirow[t]{3}{*}{ Satisfaction } & $2.6 \pm 1.1$ & $3.7 \pm 1.3$ & $4.9 \pm 1.2$ & $2.5 \pm 1.0$ & $1.9 \pm 1.1$ & $1.8 \pm 0.9$ & $0.06[-0.43$ to 0.56$]$ & .797 \\
\hline & & & & & & & $0.79[0.23$ to 0.134$]$ & .002 \\
\hline & & & & & & & $2.71[2.22$ to 3.20$]$ & $<.001$ \\
\hline \multirow[t]{3}{*}{ Pain } & $4.2 \pm 1.4$ & $4.5 \pm 1.3$ & $4.7 \pm 1.2$ & $3.9 \pm 1.4$ & $3.8 \pm 1.4$ & $3.4 \pm 1.5$ & $0.22[-0.44$ to 0.89$]$ & .509 \\
\hline & & & & & & & $0.75[0.11$ to 1.39$]$ & .022 \\
\hline & & & & & & & $1.28[0.64$ to 1.91$]$ & $<.001$ \\
\hline \multirow{3}{*}{$\begin{array}{l}\text { Total FSFI } \\
\text { score }\end{array}$} & $18.3 \pm 6.7$ & $22.3 \pm 6.9$ & $26.0 \pm 6.7$ & $18.0 \pm 6.0$ & $15.9 \pm 6.8$ & $13.5 \pm 6.3$ & $0.38[-2.62$ to 3.39$]$ & .800 \\
\hline & & & & & & & $6.41[3.19$ to 9.63$]$ & $<.001$ \\
\hline & & & & & & & 12.55 [9.49 to 15.60$]$ & $<.001$ \\
\hline
\end{tabular}

Note. Baseline assessment done at the initial interview. The $1^{\text {st }}$ follow-up was done between $28-30$ weeks of gestation, while the $2^{\text {nd }}$ follow-up was done between $10-12$ weeks postpartum

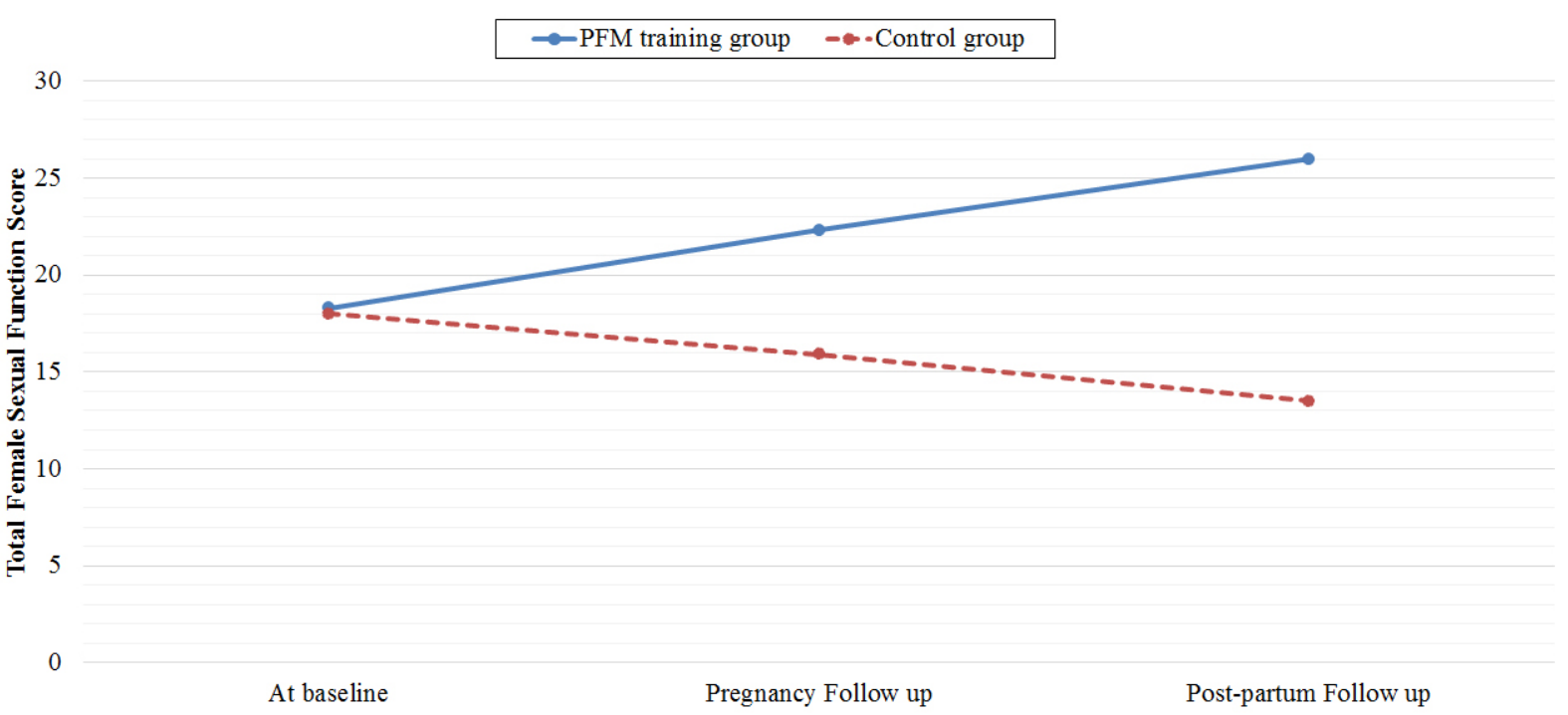

Figure 2. Total FSFI score at baseline, pregnancy follow-up, and post-partum follow-up by the study groups 


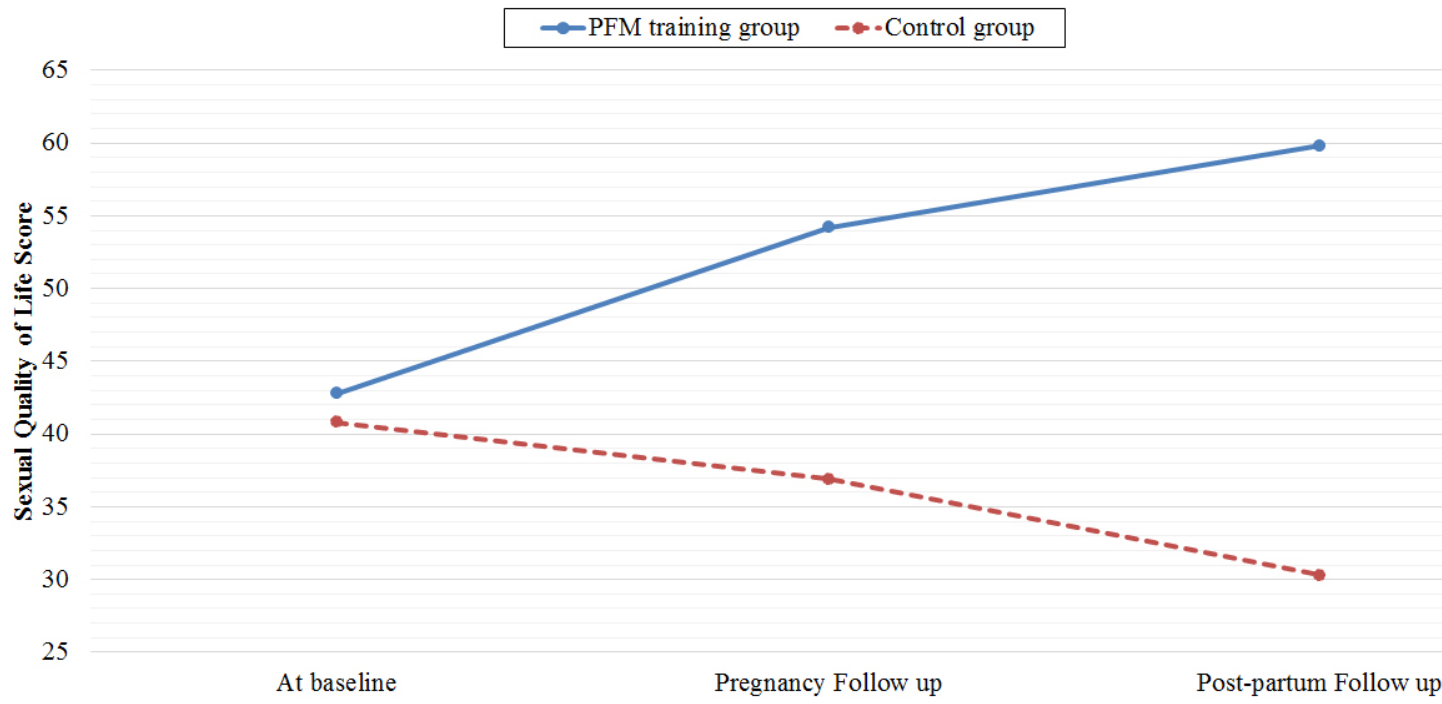

Figure 3. Total FSFI score at baseline, pregnancy follow-up, and post-partum follow-up by the study groups

Table 4. Sexual Quality of Life Score at baseline, pregnancy and post-partum follow-ups by the study groups $(\mathrm{n}=72)$

\begin{tabular}{|c|c|c|c|c|c|}
\hline \multirow[t]{2}{*}{ SQOL-F score } & \multirow{2}{*}{$\begin{array}{l}\begin{array}{l}\text { PFM training group } \\
(\mathrm{n}=36)\end{array} \\
\text { Mean } \pm S D\end{array}$} & \multirow{2}{*}{$\begin{array}{c}\text { Control group } \\
(\mathrm{n}=36)\end{array}$} & \multirow{2}{*}{$\begin{array}{c}\text { Mean difference } \\
{[95 \% \mathrm{CI}]}\end{array}$} & \multicolumn{2}{|c|}{ Student's $t$ test } \\
\hline & & & & $t$ & $p$ \\
\hline At baseline & $42.8 \pm 12.2$ & $40.8 \pm 10.3$ & $2.06[-3.26-7.37]$ & 0.772 & .443 \\
\hline Pregnancy Follow up & $54.2 \pm 15.9$ & $36.9 \pm 9.7$ & 17.33 [11.14-23.53] & 5.583 & $<.001$ \\
\hline Post-partum Follow up & $59.8 \pm 13.5$ & $30.3 \pm 7.0$ & 29.47 [24.42-34.52] & 11.634 & $<.001$ \\
\hline
\end{tabular}

Table 5. The pelvic floor muscle strength at different time points by the study groups $(\mathrm{n}=72)$

\begin{tabular}{|c|c|c|c|c|c|c|}
\hline \multirow{2}{*}{ Degree of PFM contraction } & \multicolumn{2}{|c|}{ PFM training group $(n=36)$} & \multicolumn{2}{|c|}{ Control group $(n=36)$} & \multicolumn{2}{|c|}{ Chi square test } \\
\hline & $\mathbf{N}$ & $\%$ & $\mathbf{N}$ & $\%$ & $\chi^{2}$ & $p$ \\
\hline \multicolumn{7}{|l|}{ At baseline } \\
\hline Flicker & 3 & 8.3 & 4 & 11.1 & & \\
\hline Weak & 14 & 38.9 & 13 & 36.1 & & \\
\hline Moderate & 9 & 25.0 & 9 & 25.5 & & \\
\hline Good & 7 & 19.5 & 6 & 16.6 & & \\
\hline Strong & 3 & 8.3 & 4 & 11.2 & 0.400 & .982 \\
\hline \multicolumn{7}{|l|}{ At $1^{\text {st }}$ follow-up } \\
\hline Flicker & 1 & 5.6 & 3 & 8.3 & & \\
\hline Weak & 5 & 13.9 & 12 & 33.4 & & \\
\hline Moderate & 7 & 19.5 & 11 & 30.6 & & \\
\hline Good & 11 & 30.6 & 6 & 16.6 & & \\
\hline Strong & 12 & 33.4 & 4 & 11.2 & 10.242 & .037 \\
\hline \multicolumn{7}{|l|}{ At $2^{\text {nd }}$ follow-up } \\
\hline Flicker & 0 & 0.0 & 3 & 8.3 & & \\
\hline Weak & 6 & 16.6 & 12 & 33.4 & & \\
\hline Moderate & 5 & 13.9 & 13 & 36.1 & & \\
\hline Good & 13 & 36.1 & 3 & 8.3 & & \\
\hline Strong & 12 & 33.4 & 5 & 13.9 & 17.688 & .0014 \\
\hline
\end{tabular}

Note. Baseline assessment was done at the initial interview. The $1^{\text {st }}$ follow-up was done between 28-30 weeks of gestation, while the $2^{\text {nd }}$ follow-up was done between 10-12 weeks postpartum. 


\section{Discussion}

This study aimed to evaluate effectiveness of pelvic floor muscles training on females' sexual function throughout pregnancy and postpartum. This aim was achieved where the present study findings revealed a significant improvement in the female sexual function, sexual quality of life, and strength of the PFM in the training group compared to the control group during pregnancy and postpartum follow-ups.

The PFM training group of the present study showed a higher increase in the total FSFI score equated to the control group by a mean difference of 6.4 and 12.5 points; respectively at the pregnancy and postpartum follow-ups. Additionally, all sexual function domains were significantly higher in the training group subjects compared to those of the control group. Thus, the first study hypothesis was accepted "Pregnant women who train their pelvic floor muscles during the pregnancy and postpartum period, show a significant increase of the total female sexual function index and sexual domains scores compared to those who do not train".

Closely related to the current study results are those of an Iranian randomized controlled trial. ${ }^{[18]}$ Such a study had examined the influence of a PFM training on sexual function of 84 women. They have initiated the PFM training at early pregnancy and maintained three months postpartum. The study evidenced that the FSFI total scores were higher in the PFM training group than in the control group by 8.2 points at the pregnancy follow-up and 12.7 points at the postpartum follow-up compared to the baseline scores. All sexual function domains were significantly higher at the pregnancy and postpartum assessments in the PFM training group compared to the control group of the same Iranian study. ${ }^{[19]}$ Similarly, a significant improvement of one or more sexual domains was proved in the PFM training groups of a large systematic review involved eight randomized controlled trials on 1431 heterogeneous women. ${ }^{[20]}$ Among these trials, a Turkish trial involved 75 postpartum primiparous women, ${ }^{[21]}$ concluded that initiating PFM exercise at early puerperium provides a promise of a significant increase in the total FSFI score and most of the sexual domains scores.

This improvement of the female sexual function may be related to the strengthening of the pelvic floor muscles evidenced in the present study. There is a notion that increasing the PFM strength is associated with the strengthening of the clitoral attached muscles. It causes enhancement in the sensitivity of the clitoris and pelvic blood flow. These actions, in turn, improve the PFM reflex contraction; thus sexual domains of lubrication, arousal, and orgasm. ${ }^{[22]}$ Another rationale that may explain the sexual function improvement is that the unintentional contraction of the PFM may cause el- evation of the uterus, increase vaginal length and tightening; consequently improves the sexual function score. ${ }^{[23,24]}$

The current study findings revealed a significant increase in the SQOL-F score in the PFM training group equated to the control group by mean differences of 11.4 points at the first follow-up and 17 points at the second follow-up. Supporting the second study hypothesis "Pregnant women who train their pelvic floor muscles during the pregnancy and postpartum period, demonstrate a significant increase of the sexual quality of life-female score compared to those who do not train". An Iranian study had revealed a higher SQOL-F score in the training group; at pregnancy follow-up by 18.5 points and at postpartum follow-up by 31.8 points than the baseline score, compared to the non-significant change in the control group. ${ }^{[18]}$ This result is consistent with that of the present study. This agreement between the present study finding and that of the Iranian one may be related to the similarity of the subjects' inclusion criteria.

The present study findings showed that despite there was no significant difference at baseline assessment, there was an increase in the subjects' frequency displaying good to strong PFM contractions in the training group equated to the control group at pregnancy follow-up and greater increase at the postpartum evaluation. Thus, the third study hypothesis was confirmed: "Pregnant women who train their pelvic floor muscles during the pregnancy and postpartum periods, exhibit a significant improvement in the pelvic floor muscles degree of contraction; according to the Oxford grading scale, compared to those who do not train".

This finding is in agreement with that of Pourkhiz et al. $2017,{ }^{[19]}$ who demonstrated a highly significant increase in PFM strength in the training group at pregnancy and postpartum evaluation. In another way, Dinc et al. ${ }^{[25]}$ measured the PFM strength in 40 Turkish pregnant mothers by using a perineometer vaginal sensor; after two weeks of PFM training. Dinc and coauthors found the post-training value was higher than that of the baseline by $8 \mathrm{~cm} \mathrm{H} 2 \mathrm{O}$. Similarly, a national study conducted at Qasr-Eleni hospital, Egypt on 30 mothers trained their PFM for three months post vaginal delivery, found the post-training value was higher than that of the pre-training by $25.29 \mathrm{~cm} \mathrm{H}_{2} \mathrm{O} .^{[26]}$ The greater increase achieved by the Egyptian mothers compared to that of the Turkish mothers may be attributed to the longer period of performing the PFM training; three months versus two weeks respectively.

\subsection{Limitations of the study}

Two limitations were noticed in this study. The assessor was not blinded for the group's allocation in evaluating the 
strength of the pelvic floor muscle during the follow-ups. This limitation may increase the risk of bias. Investigating the effect of the exercise on nulliparous only may limit the generalizability of the findings. On the other hand, keen of the researcher to retain the participants of the study by continuous follow-ups; resulting in a low attrition rate, increase the weight of this study.

\subsection{Implications in nursing practice}

Initiating PFM training at early pregnancy and continuing it during postpartum seems to be an effective option for strengthening the weakened PFM. It is a painless gratis cure. It can be performed at any time and in different positions. No side effects can result from performing PFM exercise. ${ }^{[6]}$ Consequently, integrating PFM exercise training in nursing practice can be suggested at antenatal outpatient clinics.

\section{CONCLUSION AND RECOMMENDATIONS}

Depending on the current study findings, the three tested hypotheses were accepted. There was a significant improvement in female sexual function, sexual quality of life-female, and pelvic floor muscle strength during pregnancy and postpartum follow-ups among the PFM training group compared to the control group. Hence, the following can be recommended:

(1) Implementing PFM exercise training at early gestation weeks and maintaining during the postpartum period can be advised.

(2) Future research trials can be directed to involve multipara women, recruiting from different institutions, and studying larger sample sizes.

\section{Conflicts of InTEREST Disclosure}

The authors declare they have no conflicts of interest.

\section{REFERENCES}

[1] Collumbien M, Bussa J, Cleland J, et al. Social science methods for research on sexual and reproductive health. World Health Organization. 2012; 1-12.

[2] Leite APL, Moura EA, Campos AAS, et al. Validação do índice da função sexual feminina em grávidas brasileiras. Revista brasileira de ginecologia e obstetrícia. 2007; 29(8): 396-401. https : //doi.or g/10.1590/S0100-72032007000800003

[3] Jamali S, Mosalanejad L. Sexual dysfunction in Iranian pregnant women. Iranian Journal of Reproductive Medicine. 2013 Jun; 11(6) 479-86.

[4] Pastore L, Owens A, Raymond C. Postpartum sexuality concerns among first-time parents from one U.S. academic hospital. The Journal of Sexual Medicine. 2007; 4(1): 115-23. PMid: 17087807. https://doi.org/10.1111/j.1743-6109.2006.00379.x

[5] Melanie J, Gembeck Z. Young females' sexual self efficacy: Associations with personal autonomy and the couple relationship. Sex Health. 2013; 10: 204-10. PMid: 23591062. https ://doi .org/10 $.1071 / \mathrm{SH} 12139$

[6] Modarres M, Rahimikian F, Booriaie E. Effect of pelvic muscle exercise on sexual satisfaction among primiparous women. Journal of Nursing and Midwifery Tehran University of Medical Sciences. 2012; 18: 108

[7] Graziottin A, Bø K, Berghmans B, et al. Evidence Based Physical Therapy for the Pelvic Floor. Bridging Science and Clinical Practice, 2nd ed. Philadelphia: Churchill Livingstone Elsevier; 2015. 243-70 p.

[8] Riazi H, Bashirian S, Ghelichkhani S. Kegel exercise application during pregnancy and postpartum in women visited at Hamadan health care centers. Iranian Journal Obstetrics Gynecology Infertility. 2007; 10: 47-54.

[9] Martinez CS, Ferreira FV, Castro AAM, et al. Women with greater pelvic floor muscle strength have better sexual function. Acta $\mathrm{Ob}$ stetricia et Gynecologica Scandinavica. 2014; 93: 457-502. PMid: 24628380. https://doi.org/10.1111/aogs. 12379
[10] Braekken IH, Majida M, Ellstrom EM, et al. Can pelvic floor muscle training improve sexual function in women with pelvic organ prolapse? A randomized controlled trial Journal Sexual Medicine. 2015; 12: 470-80. PMid: 25401779. https ://doi.org/10.1111/jsm. 12746

[11] Baytur YB, Deveci A, Uyar Y, et al. Mode of delivery and pelvic floor muscle strength and sexual function after childbirth. International Journal Gynecology Obstetrics. 2005; 88: 276-80. PMid: 15733881. https://doi.org/10.1016/j.ijgo.2004.12.019

[12] de Andrade RL, Bø K, Antonio FI, et al. An education program about pelvic floor muscles improved women's knowledge but not pelvic floor muscle function, urinary incontinence or sexual function: a randomized trial. Journal of Physiotherapy. 2018; 64: 9196. PMid: 29574170. https ://doi.org/10.1016/j.jphys. 20 18.02 .010

[13] Elnashar A, EL-Dien Ibrahim M, EL-Desoky M, et al. Female sexual dysfunction in Lower Egypt. BJOG. 2007; 114: 201-206. PMid: 17305892. https://doi.org/10.1111/j.1471-0528.2006.0 $1106 . \mathrm{x}$

[14] Malakoti1 J, Zamanzadeh V, Maleki A, et al. Sexual Function in Breastfeeding Women in Family Health Centers of Tabriz, Iran, 2012. Journal of Caring Sciences. 2013; 2(2): 141-146.

[15] Anis TH, Gheit SA, Saied HS, et al. Arabic translation of Female Sexual Function Index and validation in an Egyptian population. Journal Sexual Medicine. 2011 Dec; 8(12): 3370-3378. PMid: 21995610. https://doi.org/10.1111/j.1743-6109.2011.02471.x

[16] Symonds T, Boolell M, Quirk F. Development of a Questionnaire on Sexual Quality of Life in Women. Journal of Sex and Marital Therapy. 2005; 31(5): 385-397. PMid: 16169822. https: //doi.org/10.1080/00926230591006502

[17] Laycock J, Jerwood D. Pelvic floor muscle assessment: The perfect scheme. Physiotherapy. 2001; 87: 631-42. https://doi.org/10 .1016/S0031-9406(05)61108-X

[18] Pourkhiz Z, Charandabi S, Mirghafourvand M, et al. Effect of Pelvic Floor Muscle Training on Female Sexual Function During Preg- 
nancy and Postpartum: A Randomized Controlled Trial. Iranian Red Crescent Medicine Journal. 2018 October; 19(10): e63218. https://doi.org/10.5812/ircmj.63218

[19] Laycock J. Female pelvic floor assessment: the Laycock ring of continence. J Natl Women Health Group Aust Physiother Assoc. 1994; 40-51.

[20] Ferreira CH, Dwyer PL, Davidson M, et al. Does pelvic floor muscle training improve female sexual function? A systematic review. International Urogynecology Journal. 2015; 26(12): 1735-50. PMid: 26072126. https ://doi.org/10.1007/s00192-015-2749-y

[21] Citak N, Cam C, Arslan H, et al. Postpartum sexual function of women and the effects of early pelvic floor muscle exercises. Acta Obstetricia et Gynecologica Scandinavica. 2010; 89(6): 817-22. PMid: 20397759. https://doi.org/10.3109/00016341003801623

[22] Graber B, Kline-Graber G. Female orgasm: role of pubococcygeus muscle. Journal Clinical Psychiatry. 1979; 40(8): 348-51.
[23] Shafik A. The role of the levator ani muscle in evacuation, sexual performance and pelvic floor disorders. International Urogynecology Journal Pelvic Floor Dysfunction. 2000; 11(6): 361-76. PMid: 11147745. https://doi.org/10.1007/PL00004028

[24] Ma Y, Qin H. Pelvic floor muscle exercises may improve female sexual function. Medical Hypotheses. 2009; 72(2): 223. PMid: 19004565. https ://doi.org/10.1016/j.mehy.2008.09.026

[25] Dinc A, Kizilkaya Beji N, Yalcin O. Effect of pelvic floor muscle exercises in the treatment of urinary incontinence during pregnancy and the postpartum period. International Urogynecology Journal Pelvic Floor Dysfunction. 2009; 20 (10): 1223-31. PMid: 19649552. https://doi.org/10.1007/s00192-009-0929-3

[26] El-begway A, El-shamy F, Hanfy H. The Effect of Pelvic Floor Exercise on Sexual Function after Vaginal Delivery. Med. J. Cairo University. 2010 Sep; 78(2): 27-31. 